\title{
Kelola
}

Jurnal Manajemen Pendidikan

Magister Manajemen Pendidikan

e-ISSN 2549-9661

FKIP Universitas Kristen Satya Wacana

Volume: 5, No. 1, Januari-Juni 2018

jurnalkelola@gmail.com

\section{Peran Kepala Sekolah Dalam Meningkatkan Kinerja Guru}

\author{
Nasib Tua Lumban Gaol \\ Pendidikan Agama Kristen, STT Anugerah Sinagoge Medan \\ nasib.t.lumbangaol@gmail.com \\ Paningkat Siburian \\ Manajemen Pendidikan, Pascasarjana Universitas Negeri Medan \\ siburianpaningkat@gmail.com
}

\begin{abstract}
The purpose of this study was to explore how the principal should work at school. Six efforts can be implemented by school principal in enhancing the teacher's performance including (1) to focus seriously on the improvement of teacher competencies, (2) to provide sufficient funding for improving teacher professionalism, (3) to supervise and guide teachers professionally, (4) to create a organizational culture of school that are comfortable for teachers, (5) to create innovation and advancement at school, and (6) to provide various rewards for each achievement that are done by teacher. Hence, it is recommended that school principal must more actively and creatively collaborate with teachers and educational stakeholder to conduct the improvement of teachers' performance.
\end{abstract}

Keywords: Education, School Principal, Teacher Performance

\section{Article Info}


Peran Kepala Sekolah Dalam Meningkatkan Kinerja Guru | Nasib Tua Lumban Gaol \& Paningkat Siburian

\section{PENDAHULUAN}

Kualitas pendidikan sangat ditentukan oleh proses pembelajaran di lembaga pendidikan (Lumban Gaol, 2017), misalnya, sekolah. Selain itu, kepala sekolah dan guru merupakan penggerak utama yang berpengaruh signifikan terhadap setiap pelaksanaan proses pembelajaran siswa selama berada di lingkungan sekolah. Tanpa adanya kinerja guru yang baik dan peran kepala sekolah yang memadai dalam mengelola sekolah, sangat sulit meningkatan kualitas pendidikan atau mencapai standar nasional pendidikan.

Dalam Undang Undang Sistem Pendidikan Nasional Nomor 20 Tahun 2003, Bab IX Pasal 35 ayat 1, terdapat delapan komponen standar pendidikan Nasional, yaitu isi, proses, kompetensi lulusan, tenaga kependidikan, sarana dan prasarana, pengelolaan, pembiayaan, dan penilaian pendidikan. Kedelapan komponen tersebut harus ditingkatkan secara berencana dan berkala supaya ada perubahan mendasar. Oleh karena itu, untuk mencapai kedelapan komponen pendidikan nasional yang demikian, maka kualitas proses pembelajaran di sekolah adalah sebagai penentu. Pembelajaran di sekolah akan berhasil apabila kepala sekolah mampu mengelola dan memimpin sekolah dengan baik. Kemampuan kepala sekolah dalam mengelola dan memimpin sekolah ditunjukkan dari kepemimpinan yang dimiliki dalam upaya mewujudkan sekolah sebagai wadah pembelajaran yang efektif dan efisien.

Pada hakikatnya, kepemimpinan memainkan peran yang begitu penting dan memiliki fungsi sebagai penentu keberhasilan kelompok atau organisasi apapun (Okoroji, Anyanwu \& Ukpere, 2014). Hal senada dikemukakan Igwe dan Odike (2016) yang menegaskan bahwa sama seperti organisasi lainya, keberhasilan dan kegagalan sekolah sangat banyak berkaitan erat dengan kualitas kepemimpinan yang dimiliki oleh kepala sekolah. Oleh karena itu, sekolah sebagai organisasi pendidikan harus dipimpin kepala sekolah yang dapat memfungsikan peran kepemimpinannya dengan baik. Tan (2016) menyatakan bahwa kepala sekolah sebagai pemimpin pendidikan memiliki empat fungsi, yaitu (1) managing the teaching-learning program, (2) designing the organization to emphasize collaborative decision-making processes among different stakeholders, (3) developing an academic school vision and giving directions, (4) understanding and developing teachers.

Peran yang dimiliki oleh kepala sekolah memang begitu kompleks. Selain berperan mengelola sekolah supaya menjadi efektif dan efisien, kepala sekolah secara khusus juga harus mampu meningkatkan kinerja guru. Susanto (2016) menyatakan bahwa peningkatan kinerja guru dalam pembelajaran dapat tercapai apabila kepala sekolah sebagai pemimpin mampu memacu guru dalam meningkatakan kinerja para guru dengan sungguh-sungguh dan penuh dedikasi yang tinggi terhadap tugas yang diemban. Oleh karena itu, tanpa adanya dukungan yang memadai dari kepala sekolah untuk peningkatan kinerja guru, maka guru tidak akan pernah melaksanakan tugasnya, yaitu mendidik, melatih, membimbing, dan mengembangkan potensi setiap siswa, dengan maksimal. Dengan demikian, untuk memperbaiki kualitas kinerja guru, maka peran kepala sekolah sebagai pemimpin pendidikan perlu dikembangkan lebih lagi supaya terjadi peningkatan kinerja guru.

Saat ini, upaya perbaikan kinerja guru di Indonesia sudah mendesak untuk dilakukan. Rendahnya kinerja guru merupakan indikasi dari rendahnya kemampuan kepala sekolah dalam menjalankan perannya sebagai pemimpin pendidikan. Akibatnya, kondisi tersebut tidak hanya berdampak pada guru 
Kelola: Jurnal Manajemen Pendidikan, Vol. 5, No. 1, Januari-Juni 2018

tetapi juga pada siswa. Potensi siswa tidak tergali dan terkembangkan secara maksimal.

Berdasarkan data yang dipublikasikan oleh Organization for Economic Co-operation and Development (OECD) pada tahun 2015, dilaporkan bahwa: "Principals in Indonesia need support to develop the skills that will enable them to play their role in managing teacher induction, performance assessments and appraisals; the monitoring, promoting, and sanctioning of teachers; the dissemination of information about teacher performance; and accountability for overall school performance." Kondisi yang diutarakan oleh OECD tersebut mengindikasikan bahwa kepala sekolah belum mampu melakukan perannya sebagai kepala sekolah dengan baik di Indonesia sehingga berdampak pada rendahnya kinerja guru. Sumintono, Sheyoputri, Jiang, Misbach dan Jumintono (2015) menyarankan bahwa persiapan dan pengembangan kepemimpinan kepala sekolah sangat penting untuk dilakukan karena berfungsi sebagai fundamental untuk peningkatan sekolah dan sistem pendidikan. Selain itu, Susanto (2016) menyatakan bahwa peran kepala sekolah sangat berpengaruh di lingkungan sekolah terutama terhadap staf pengajar atau guru. Hasil studi Supovitz, Sirinides dan May (2010) menunjukkan betapa pentingnya kerja kepala sekolah pada pembelajaran siswa karena berpengaruh secara tidak langsung pada kegiatan guru melalui peningkatan kalaborasi dan komunikasi ketika pengajaran.

Dengan demikian, studi ini berupaya untuk memberikan kontribusi pada peningkatan pengetahuan tentang peran yang harus dilakukan oleh kepala sekolah supaya terjadi peningkatan kinerja guru melalui peran yang dapat dilakukan oleh kepala sekolah. Oleh karena itu, perumusan masalah dalam studi ini adalah apakah peran yang harus dilakukan oleh kepala sekolah supaya kinerja guru dapat meningkat ketika mengelola lembaga pendidikan (sekolah)?

Karya tulis ini ditujukan untuk mengeksplorasi tentang pentingnya peran kepala sekolah dalam meningkatkan kinerja guru. Selain itu, studi ini bertujuan untuk menguraikan upaya yang harus dilakukan oleh kepala sekolah supaya kinerja guru dapat meningkat. Karya tulis ini akan berkontribusi baik secara teoritis maupun praktis. Secara teoritis, dapat menambah pengetahuan tentang peranan kepala sekolah dalam peningkatan kinerja guru. Secara praktis, dapat menambah pengetahuan kepala sekolah dalam melaksanakan perannya sebagai pemimpin pendidikan di sekolah. Melalui hasil studi ini, baik pemerintah daerah maupun pemerintah pusat dapat dibantu dalam peningakatan profesionalisme guru dan peran kepala sekolah.

\section{PEMBAHASAN}

Kepala sekolah sebagai pemimpin sekolah, memang tidak bisa dipisahkan dari berbagi tugas yang diembannya, misalnya, sebagai administrator, pengelola berbagai sumber daya yang ada di sekolah, dan pemimpin pengajaran. Kepala sekolah yang menjabat sebagai tenaga fungsional harus memiliki kompetensi profesional sebagai pemimpin sekolah. Merujuk pada Surat Keputusan Menteri Penertiban Aparatur Negara Nomor 296 tahun 1996 tentang Jabatan Guru, dinyatakan bahwa kepala sekolah adalah guru yang mendapat tugas tambahan. Dengan kata lain, kepala sekolah harus memiliki kemampuan manajerial dan kepemimpinan supaya sekolah menjadi lembaga pendidikan yang efektif dan efisien dalam melaksanakn proses pembelajaran. Atau dengan kata lain, sekolah sebagai pusat pembelajaran haruslah berkualitas. Dalam peningkatan kualitas sekolah, kepemimpinan kepala sekolah merupakan komponen yang paling penting dalam penenetuan keputusan yang berkaitan 
Peran Kepala Sekolah Dalam Meningkatkan Kinerja Guru | Nasib Tua Lumban Gaol \& Paningkat Siburian

dengan berbagai kegiatan di sekolah (Yunus, Andari \& Islam, 2017).

Meskipun kepala sekolah memiliki tanggung jawab yang begitu kompleks, tetapi upaya peningkatan kinerja guru harus tetap dilakukan. Kepala sekolah harus lebih memfokuskan perhatian dan melakukan berbagai upaya pada kepemimpinan pengajaran. Kondisi ini dikarenakan kepala sekolah sebagai pemimpin pengajaran adalah sebagai model, pelatih, fasilitator, dan pembimbing, bukan wali atau pengatur pengajaran (Bredeson \& Johansson, 2000). Artinya, ketika kepala sekolah datang melakukan supervisi pengajaran guru ke dalam kelas, kepala sekolah tidak boleh berperan sebagai evaluator atau hakim. Namun, ketika kepala sekolah melakukan supervisi maka harus menerapkan lima prinsip penting, yaitu (1) hubungan konsultatif, kolegial dan bukan hirarkhis, (2) dilaksanakan secara demokratis, (3) berpusat pada guru, (4) berdasarkan kebutuhan, dan (5) adanya bantuan professional (Mulyasa, 2005).

Bredeson dan Johansson (2000) menemukan empat bidang penting yang berdampak pada pengajaran guru di sekolah yang perlu dilakukan oleh kepala sekolah, yaitu: (1) kepala sekolah sebagai pemimpin pengajaran, (2) kepala sekolah sebagai pencipta lingkungan pembelajaran, (3) kepala sekolah terlibat secara langsung dalam mendesain, menyampaikan dan menentukan konten pengembangan profesionalitas guru, dan (4) kepala sekolah menilai hasil pengembangan profesionalitas guru. Keempat bidang tersebut dapat diimplementasikan oleh kepala sekolah dengan baik apabila kepala sekolah memahami dan melakukan peran dan tanggung jawabnya dengan sepenuh hati.

Dalam konteks pendidikan, kepala sekolah merupakan tokoh kunci bagi keberhasilan sekolah (Suhardiman, 2012; Wiyono, 2017). Kemajuan atau kemunduran kualitas pembelajaran di sekolah dipengaruhi oleh kualitas peran yang dilakukan oleh kepala sekolah. Semakin memadai pemahaman kepala sekolah dalam melakukan peranannya sebagai kepala sekolah, maka kinerja guru dan kualitas pembelajaran juga cenderung membaik.

Selain menjadi katalisator dan mediator yang menerjemahkan kebijakan pemerintah pusat, kepala sekolah juga harus mampu menyampaikan aspirasi warga sekolah atau steakholder kepada pemerintah. Ini bertujuan supaya terjadi kesesuain kebijakan dengan realitas di lapangan. Tanpa adanya tindakan kepala sekolah yang sesuai untuk menjembatani hal tersebut, kondisi sekolah akan cenderung statis atau tidak mengalami kemajuan.

Peran kepala sekolah dalam peningkatan kinerja guru adalah begitu penting. Kepala sekolah harus lebih fokus memberikan perhatian pada kegiatan-kegiatan dalam upaya memperbaiki dan meningkatkan mutu belajar melalui perbaikan kinerja guru yang ditanganinya (Susanto, 2016). Hasil kajian dari Emmanouil, Osia dan ParaskeviIoanna (2014) dinyatakan bahwa kepemimpinan kepala sekolah merupakan mediator yang membangkitkan inspirasi, motivasi, dukungan dan bimbingan sehingga mengarahkan keluarnya potensi maksimum guru dan tercapainya peningkatan kualitas sekolah. Hasil studi Hasan (2017) menunjukkan bahwa kepemimpinan kepala sekolah berpengaruh terhadap kinerja guru.

Pada hakekatnya, konsep kinerja lebih fokus pada kemampuan individu dalam mengerjakan tugas dan tanggung jawabnya supaya tujuan organisasi dapat tercapai (Siburian, 2014; Pangaribuan, Siburian, Manullang, 2016). Pangaribuan (2016) menyatakan kinerja mengarah pada penilaian terhadap pengetahuan, sikap, dan perilaku dalam bekerja yang berorientasi pada kuantitas, kualitas dan akuntabel sesui dengan standar kerja yang ditetapkan. Dari pengertian 
tersebut, kinerja mencakup kognitif, afektif dan psikomotirik yang dimiliki seseorang dalam mengerjakan tugas-tugas yang sudah diberikan.

Arman, Thalib dan Manda (2016) menyatakan kinerja guru (teacher performance) is a presentation of the work done by teachers in carrying out his duties as a professional educator. Defenisi yang lebih luas disampaikan oleh Igwe dan Odike (2016) yang menyatakan bahwa kinerja guru dapat digambarkan sebagai tugus-tugas yang dikerjakan oleh guru pada waktu yang diberikan di sekolah dalam upaya mencapai tujuan sekolah sehari-hari, tujuan kelas dan seluruh tujuan dan sasaran pendidikan. Dengan demikian, kinerja guru mencakup tugas-tugas yang dikerjakan berdasarkan tugas-tugas yang diberikan di sekolah.

Adanya berbagai tugas atau tanggung jawab yang dimiliki oleh guru, maka dukungan dari kepala sekolah sangat dibutuhkan oleh guru dalam pengerjaan tugas dan tanggung jawabnya tersebut. Apabila kepala sekolah tidak memberikan perhatian serius terhadap kinerja guru, maka guru akan menghadapi kesulitan dalam menyelesaikan berbagai tugas yang diembannya. Karena itu, peningkatan kinerja guru dapat dilakukan oleh kepala sekolah (Hasan, 2017) sebagai bagian dari perananan yang harus dilakukan oleh pemimpin pendidikan untuk meningkatkan kualitas pemebelajaran di sekolah. Pentingnya peningkatan kinerja guru sebagai komponen peningkatan mutu pembelajaran di sekolah sejalan dengan pandangan Anugraheni, I. (2017: 211) yang menyatakan bahwa peningkatan kinerja guru dapat dikembangkan melaui pelatihan-pelatihan kompetensi guru.

Peningkatan kinerja guru dapat dilakukan oleh kepala sekolah dengan memperbaiki kompetensi guru. Kompetensi guru merupakan kecakapan atau kemampuan yang harus dimiliki oleh guru untuk mengerjakan berbagai tugas yang diembannya.
Permendiknas Republik Indonesia Nomor 16 Tahun 2007 tentang Standar Kualifikasi Akademik dan Kompetensi Guru, dinyatakan bahwa setiap guru wajib memiliki empat kompetensi utama, yaitu pedagogik, kepribadian, sosial, dan profesional. Apabila kompetensi guru semakin baik, tentu kinerja guru juga akan semakin baik. Dengan demikian, berdasarkan peran kepala sekolah, ada enam upaya yang dapat dilakukan oleh kepala sekolah supaya peningkatan kinerja guru dapat dilakukan.

Pertama, kepala sekolah harus memiliki komitmen yang tinggi terhadap peningkatan sekolah, fokus pada pengembangan kurikulum, menfasilitasi dan mendukung guru dalam pengembangan kompetensinya (Hermino, 2016). Upaya yang dapat dilakukan oleh kepala untuk meningkatkan kinerja guru adalah dengan mengarahkan guru supaya mengikuti kegiatan pendidikan dan pelatihan untuk memperbaiki kompetensinya, misalnya, mengikuti seminar atau workshop. Hosnan (2016) menyatakan bahwa untuk peningkatan kompetensi guru dibutuhkan adanya pelatihan yang disesuaikan dengan kompetensi masing-masing guru. Lebih lanjut, Mulyasa (2005) menyarankan agar peningkatan kinerja guru dapat dilakukan oleh kepala sekolah dengan melibatkan guru pada kegiatan Musyawarah Guru Mata Pelajaran (MGMP), Musyawarah Guru Pembimbing (MGP), dan Kelompok Kerja Guru (KKG).

Kedua, peran yang dapat dilakukan oleh kepala sekolah dalam upaya peningkatan kinerja guru adalah dengan mengalokasikan anggaran untuk peningkatan kompetensi guru (Hermino, 2016). Kepala sekolah harus mampu menyusun anggaran yang sesuai dengan kebutuhan sekolah termasuk kebutuhan dalam pengembangan profesionalisme guru. Dengan adanya opimalisasi dana untuk pengembangan kompetensi guru, maka proses pendidikan dan 
Peran Kepala Sekolah Dalam Meningkatkan Kinerja Guru | Nasib Tua Lumban Gaol \& Paningkat Siburian

pelatihan serta kegiatan yang berkaitan dengan pengembangan profesionalisme guru dapat berjalan dengan lancar. Upaya yang dapat dilakukan oleh kepala sekolah untuk pemantapan pendanaan dalam peningkatan kinerja guru adalah dengan mengajukan bantuan dana kepada pihak pemerintah maupun swasta.

Ketiga, kepala sekolah dapat memberikan saran dan bimbingan kepada guru atas kinerjanya dalam pembelajaran (Hermino, 2016). Artinya, ketika guru menghadapi berbagai kendala dalam pembelajaran, kepala sekolah harus memberikan bantuan supaya guru dapat menyelesaikan persoalan pembelajaran yang dihadapi. Bantuan terhadap guru yang dapat dilakukan oleh kepala sekolah, misalnya, memberikan supervisi klinis atau training lanjutan kepada guru.

Keempat, kepala sekolah harus menciptakan budaya organisasi sekolah yang kondusif supaya kinerja guru dan tenaga kependidikan tidak terganggu. Kepala sekolah juga harus mampu menciptakan budaya organisasi di sekolah sekondusif mungkin sehingga prestasi belajar siswa dan kinerja guru dapat meningkat (Lumban Gaol, 2017). Susanto (2016) menyimpulkan bahwa budaya organisasi adalah aturan main atau acuan (nilai-nilai, norma-norma, falsafah dan keyakinan) suatu organisasi atau komunitas tertentu yang dipahami oleh seluruh anggota organisasi yang dimanifestasikan dalam pola pikir dan perilaku yang terintegrasi secara internal dan adanya adaptasi secara eksternal dalam usaha mencapai tujuan orgnisasi. Lebih lanjut, Wibowo (2016) menyatakan bahwa kinerja sumber daya manusia sangat ditentukan oleh kondisi lingkungan internal maupun eksternal organisasi, termasuk budaya organisasi. Dengan adanya perasaan nyaman yang dialami oleh guru, maka akan dapat meningkatkan motivasi komitmen dan loyalitas mereka dalam mengerjakan tugustugas yang diemban (Hasan, 2017). Dengan demikian, kepala sekolah memiliki peran vital adan harus mampu menciptakan budaya organisasi dan iklim kerja kondusif di sekolah.

Kelima, kepala sekolah dapat menciptakan pembaruan, keunggulan komparatif, dan memanfaatkan berbagai peluang supaya proses pembelajaran dapat berlanngsung dengan baik. Keenam, pemberian penghargaan atas prestasi yang diperoleh guru haruslah menjadi budaya di sekolah. Artinya, kepala sekolah harus memberikan perhatian serius terhadap pencapain-pencapaian yang sudah diperjuangkan oleh guru. Adapun keenam peranan kepala sekolah yang diuraikan sebelumnya adalah solusi untuk peningkatan kinerja guru di sekolah. Meskipun hal tersebut tidak begitu mudah untuk dilakukan, tetapi kepala sekolah dapat bekerja sama dengan steakholder pendidikan untuk mewujudkan tujuan sekolah.

\section{SIMPULAN}

Kepala sekolah adalah pemimpin pendidikan yang berperan penting dalam peningkatan kinerja guru. Upaya yang dapat dilakukan oleh kepala sekolah dalam peningkatan kinerja guru berkaitan dengan perannya sebagai pemimpin pendidikan di sekolah, yaitu: (1) memaksimalkan fokus pada peningkatan kompetensi guru, (2) mengalokasikan anggaran yang cukup untuk peningkatan profesionalisme guru, (3) memberikan saran dan bimbingan yang profesional kepada guru, (4) menciptakan budaya organisasi sekolah yang kondusif; (5) menciptakan pembaruan dan keunggulan, dan (6) memberikan reward (penghargaan) bagi guru yang berhasil atau berkinerja dengan baik.

Dengan demikian, kepala sekolah harus menjadikan sekolah sebagai wadah pembelajaran bagi setiap warga sekolah supaya terjadi proses pembelajaran yang kondusif. Kepala sekolah juga harus mampu menjadi sosok yang dapat mengayomi guru supaya guru merasa bahwa pekerjaan yang dilakukan adalah dihargai. Adanya 
keterbatasan kepala sekolah dalam melakukan perannya dalam peningkatan kinerja guru, pemerintah daerah (Dinas Pendiikan) dan pemerintah pusat (Kementerian Pendidikan dan Kebudaya) harus berupaya lebih serius memfasilitasi kepala sekolah. Dukungan dari pemerintah daerah maupun pusat sangat penting dalam peningkatan peran kepela sekolah dan kinerja guru di sekolah.

\section{DAFTAR PUSTAKA}

2010. Himpunan Peraturan Perundangundangan Sisdiknas: Sistem Pendidikan Nasional. Bandung: Fokus Media.

Anugraheni, I. 2017. Analisa Faktor-Faktor yang Mempengaruhi Proses Belajar Guru-Guru Sekolah Dasar. Kelola: Jurnal Manajemen Pendidikan, 4(2), 205-212.

Arman, A., Thalib, S. B., \& Manda, D. 2016. The effect of school supervisors competence and school principals competence on work motivation and performance of Junior High School teachers in Maros Regency, Indonesia. International Journal of Environmental and Science Education, 11 (15), 7309-7317.

Bredeson, P. V. \& Johannson, O. 2000. The school principal's role in teacher professional development. Journal of in-service education, 26(2), 385-401.

Emmanouil, K., Osia, A., \& Paraskevi-Ioanna, L. 2014. The Impact of Leadership on Teachers' Effectiveness. International Journal of Humanities and Social Science, 4(7), 34-39.

Hasan, M. N. 2017. Influence of Work Motivation, Leadership and Organizational Culture Principal of the Teacher Performance in Vocational School (SMK) Muhammadiyah, Rembang City, Central Java Province,
Indonesia. European Journal of Business and Management, 9(2), 3644.

Hermino, A. 2016. Manajemen Kemarahan Siswa. Kajian Teoritis dan Praktis dalam Manajemen Pendidikan. Yogyakarta: Pustaka Pelajar.

Hosnan, M. 2016. Etika Profesi Pendidik: Pembinaan dan Pemantapan Kinerja Guru, Kepala Sekolah, serta Pengawas Sekolah. Bogor: Ghalia Indonesia.

Igwe, N. N. \& Odike, M. N. 2016. A Survey of Principals' Leadership Styles Associated with Teachers' Job Performance in Public and Missionary Schools in Enugu State Nigeria. British Journal of Education, Society and Behavioural Science, 17(2), 1-21.

Lumban Gaol, N. T. 2017. Teori dan implementasi gaya kepemimpinan kepala sekolah. Kelola: Jurnal Manajemen Pendidikan, 4(2), 213219.

Mulyasa, E. 2005. Menjadi Kepala Sekolah Profesional dalam konteks menyukseskan MBS dan KBK. Bandung: PT REMAJA ROSDAKARYA.

OECD/Asian Development Bank. 2015. Reviews of national Policies for Education/ Education in Indonesia: Rising to the Challenge. Paris: OECD (Organization for Economic Cooperation and Development) Publishing.

Okoroji, L. I., Anyanwu, O. J., \& Ukpere, W. I. 2014. Impact of leadership styles on teaching and learning process in Imo State. Mediterranean Journal of Social Sciences, 5(4), 180-193.

Pangaribuan, W. 2016. Pengaruh budaya organisasi, komitmen organisasi, 
Peran Kepala Sekolah Dalam Meningkatkan Kinerja Guru | Nasib Tua Lumban Gaol \& Paningkat Siburian

komunikasi interpersonal, dan efektifitas sistem pengendalian manajemen kinerja terhadap kinerja dosen. Disertasi. Medan: Universitas Negeri Medan.

Pangaribuan, W., Siburian, P. \& Manullang, J. 2016. Determining Factors of Senior High School Principals' Performance in Medan. International Journal Basic and Applied Research (IJSBAR), 25(2), 44-57.

Permendiknas Republik Indonesia Nomor 16 Tahun 2007 tentang Standar Kualifikasi Akademik dan Kompetensi Guru.

Siburian, P. 2014. Faktor Penentu Kinerja Kepala Sekolah Menengah Kejuruan. Cakrawala Pendidikan, 32(2), 257265.

Suhardiman, B. 2012. Studi Pengembangan Kepala Sekolah: Konsep dan Aplikasi. Jakarta: Rineka Cipta.

Sumintono, B., Sheyoputri, E. Y. A., Jiang, N., Misbach, I. H. \& Jumintono. 2015. Becoming Principal in Indonesia: possibility, pitfalls and potential. Asia Pasicific Journal of Education, 1-11.

Supovitz, J., Sirinides, P., \& May, H. 2010. How principals and peers influence teaching and learning. Educational Administration Quarterly, 46(1), 3156.

Surat Keputusan Menteri Penertiban Aparatur Negara No.0296 Tahun 1996 tentang Jabatan Fungsional Guru.

Susanto, A. 2016. Konsep, Strategi, dan Implementasi Manajemen Peningkatan Kinerja Guru. Jakarta: Prenademedia Group.

Tan, C. Y. 2016. Examining school leadership effects on student achievement: the role of contextual challenges and constraints. Cambridge Journal of Education, 48(1), 21-45.

Wiyono, B. B. 2017. The Effect of Selfevaluation on the Principals' Transformational Leadership, Teachers' Work Motivation, Teamwork Effectiveness, and School Improvement. International Journal of Leadership in Education, 21 (1).

Yunus, M., Andari, K. D. W., \& Islam, M. A. 2017. The Principal's Competences In Implementing Cultural And Environmental Management Of The School In SDN 033 Tarakan. JPI (Jurnal Pendidikan Indonesia), 6(2), 263-274. 